\title{
Article
}

\section{Phytotoxicity of Tires Evaluated in Simulated Conditions}

\author{
Markéta Šourková ${ }^{1}\left(\mathbb{D}\right.$, Dana Adamcová ${ }^{1}\left(\mathbb{D}\right.$, Jan Winkler $^{2}$ and Magdalena Daria Vaverková ${ }^{1,3, * \mathbb{C}}$ \\ 1 Department of Applied and Landscape Ecology, Faculty of AgriSciences, Mendel University in Brno, \\ Zemědělská 1, 61300 Brno, Czech Republic; xsourkov@mendelu.cz (M.Š.); \\ dana.adamcova@mendelu.cz (D.A.) \\ 2 Department of Plant Biology, Faculty of AgriSciences, Mendel University in Brno, Zemědělská 1, \\ 61300 Brno, Czech Republic; jan.winkler@mendelu.cz \\ 3 Institute of Civil Engineering, Warsaw University of Life Sciences-SGGW, Nowoursynowska 159, \\ 02776 Warsaw, Poland \\ * Correspondence: magdalena.vaverkova@mendelu.cz
}

Citation: Šourková, M.; Adamcová, D.; Winkler, J.; Vaverková, M.D. Phytotoxicity of Tires Evaluated in Simulated Conditions. Environments 2021, 8, 49. https://doi.org/10.3390/ environments 8060049

Academic Editor: Dimitrios Komilis

Received: 11 April 2021

Accepted: 25 May 2021

Published: 27 May 2021

Publisher's Note: MDPI stays neutral with regard to jurisdictional claims in published maps and institutional affiliations.

Copyright: (c) 2021 by the authors. Licensee MDPI, Basel, Switzerland. This article is an open access article distributed under the terms and conditions of the Creative Commons Attribution (CC BY) license (https:/ / creativecommons.org/licenses/by/ $4.0 /)$.

\begin{abstract}
Illegal dumps and landfills with disposed of tires are a fact of today, which should not be neglected as they represent a great ecological burden for the environment, affect the surrounding nature and disturb the landscape. This research was focused on testing the phytotoxicity of aqueous leachates from the fractions of tires in two sets of experiments-to simulate laboratory conditions (tire leaching in distilled water) and natural conditions (tire leaching in water from a recipient) using the Phytotoxkit testing kit (kit for the establishment of inhibition/stimulation effect on the root development) and the watercress test of phytotoxicity (biological method for the assessment of leachate phytotoxicity). Plants whose seeds were selected for the test were watercress (Lepidium sativum L.) and white mustard (Sinapis alba L.). The aqueous leachate was tested for 38 weeks. During the experiment, physical and chemical parameters were measured at intervals of 14 days by the testing instrument HACH TEST KIT: electric conductivity (EC), amount of dissolved oxygen (LDO) and pH. Results of root growth inhibition (IR) on the seeds of Lepidium sativum L. and Sinapis alba L. exhibited values ranging from $11.73 \%$ to $47.74 \%$ in the tested samples. Results of germination index (GI) on the seeds of Lepidium sativum L. exhibited values below $66 \%$ in the tested samples, which indicated the leachate phytotoxicity. In spite of the fact that similar studies are tackling the acute toxicity of leachates from tires (particularly to algae, embryos and animals), this research brings complementary information in testing the acute phytotoxicity of tire leachates to higher plants.
\end{abstract}

Keywords: leachate; root growth inhibition; germination index; Lepidium sativum L.; Sinapis alba L.; watercress test

\section{Introduction}

Waste tires represent one of the most problematic sources of solid waste, namely due to their large volume, persistence and content of substances dangerous to the environment [1,2]. These are in particular toxic compounds such as polycyclic aromatic hydrocarbons, heavy metals ( $\mathrm{Cd}, \mathrm{As}, \mathrm{Cr}, \mathrm{Pb}$ and $\mathrm{Zn})$, and other reactive additives [3-5]. It is generally stated that the main components of tires are rubber polymers (40-60\%), soot (20-35\%) and softeners (15-20\%). Additives include activators, vulcanizing agents, accelerators and antidegradants [6,7]. Although the waste tires can be further processed (pyrolysis, recycling, retreading, etc.) [2,8-10], they occur every year in forests and at the bottoms of rivers and ponds. Such places with the occurrence of waste (tires, among other things) are called illegal dumps.

Illegal dumps arise as a result of incorrect or illegal waste disposal on sites other than those approved for landfilling and dumping [11]. Illegal uncontrolled stores of waste occur most frequently on forest margins, in ditches, on the peripheries of inhabited areas and elsewhere [12]. The reason for their coming into existence is particularly the fact that waste generators are not willing to pay for the disposal, there are not collection yards and the 
generators are not aware of the serious impacts of illegal waste dumping [11,13]. Tires are one of the waste types found on illegal dumps, even for several tens of years due to their slow rate of decomposition. The illegal dumps contaminate soils, can pollute water sources and induce changes on the Earth's surface. As pointed out by Keesstra et al. (2016), the sustainable existence of human communities depends on the reasonable usage of natural resources and care of the environment [14].

Apart from illegal dumps where they are, waste tires also get into the environment in other ways, even during the phase of their use. This mainly has to do with their fractions (in the form of nanoparticles), so-called tire wear, which occurs upon the tire contact with the road, thus polluting the environment. Over the course of years, leachates from these particles get into both surface water and groundwater [15]. Waste tires contain heavy metals and chemicals that have been proven to be carcinogenic and mutagenic [16,17]. These substances are released into the environment during their gradual decomposition, and toxins from them may contaminate the aquatic or soil environments. Contaminated soils are dangerous not only to flora and fauna but also to human health $[18,19]$. There are also increasing concerns about the effect of nanomaterials on live organisms, including higher plants. Nanoparticles can markedly change the physical and chemical characteristics of materials and can negatively affect the development and yields of higher plants. There is only limited information available about the effects of nanoparticles on higher plants [20]. Waste tires currently occur in the beds of watercourses, especially in developing countries, but developed countries are no exception either. Such a kind of waste can be potentially risky for the environment. In connection with this research, the phytotoxicity of leachates from waste tires was examined in laboratory receptacles. The phytotoxicity of leachates was ascertained, pointing to possible risks following out from illegal waste handling as well as from using it in the aqueous environment.

The phytotoxicity of leachate is generally established using GI [21,22] and IR, giving the percentage of root growth stimulation or inhibition $[21,23,24]$. These two indices are the most sensitive parameters of relative germination of seeds and relative elongation of roots, which take into account both the low toxicity affecting root development and the high toxicity affecting germination $[23,25]$. Tests of phytotoxicity are considered as a method of highly reproducible screening of wastewater samples, sediments, soils, sewer sludge and leachates, serving to reveal their possible toxicity to plants [26]. With the current annual global production of tires reaching approximately one billion, the number of waste tires is expected to increase gradually [27]. The evaluation of their impact on the environment is therefore very important. The goal of this study was: (a) to determine the degree of phytotoxicity of leachates from waste tires in laboratory conditions and (b) to monitor the variability of physical and chemical parameters of leachates from waste tires over time.

\section{Materials and Methods}

In this study, a waste tire was chosen after the end of its service life, washed and then cut by the machine into small fractions sized ca. $10 \times 4 \mathrm{~cm}$. The tire fractions were placed into two glass receptacles of $4.5 \mathrm{~L}$ in volume. The first receptacle was filled with distilled water (laboratory conditions), and the second one was filled with water from a recipient (simulation of real conditions). The tire fragments were left to leach for 8 months. During that period, physical and chemical parameters were measured, and after the period was over, the leachates were subjected to the phytotoxicity tests (Figure 1). Data analysis in the below graphs (Figures 2-6) shows the range of allowed errors and standard deviations. These line segments are shown in all data points in data. Together with the results, standard errors are shown, which were created using the Microsoft Excel tabular processor, and subsequently, statistical analyzes were performed (computer program STATISTICA). 


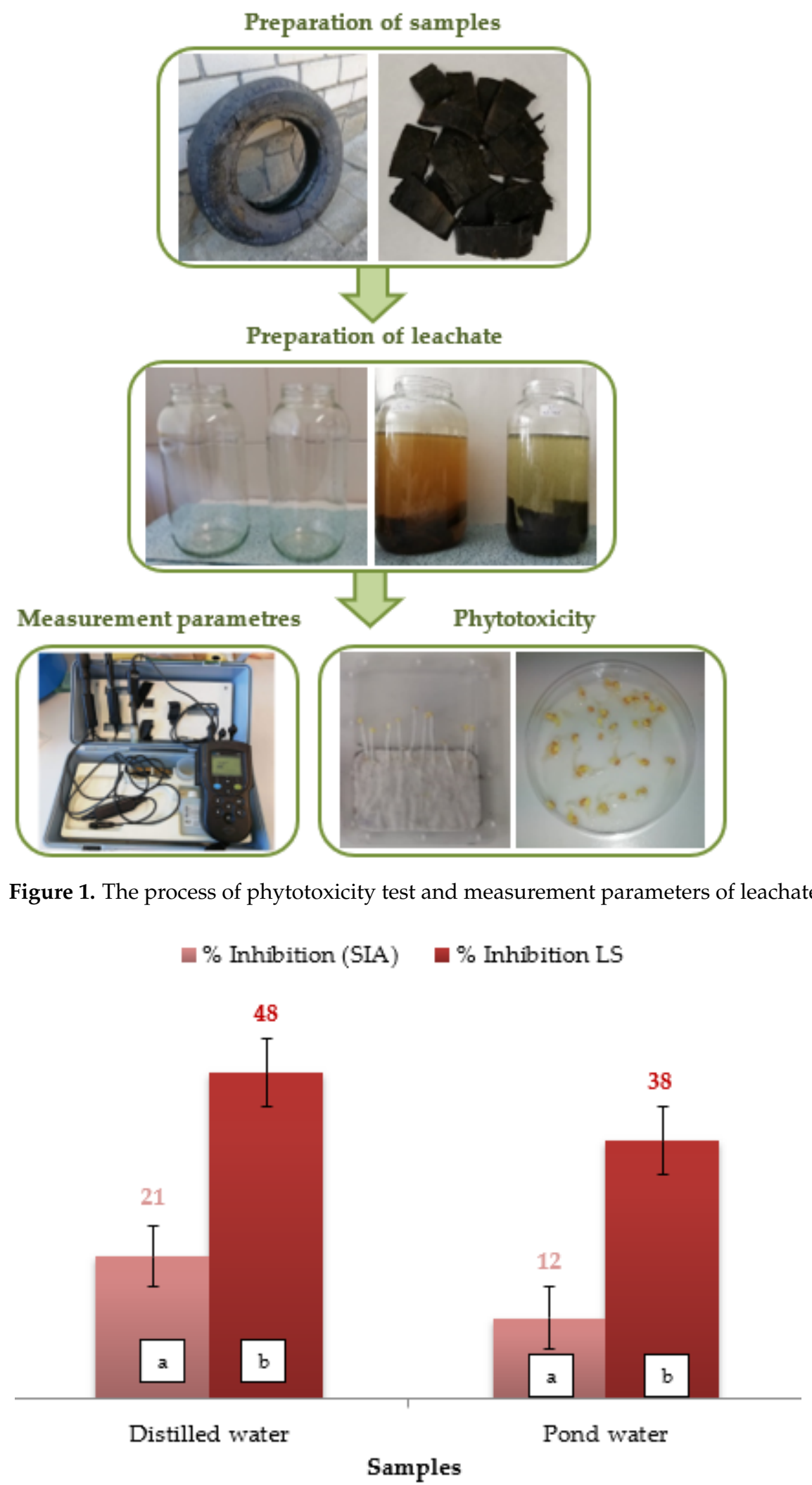

Figure 2. Inhibition of root growth (IR) in Sinapis alba L. (SIA) and Lepidium sativum L. (LS) in the test of phytotoxicity. 


\section{— GI [\%]}

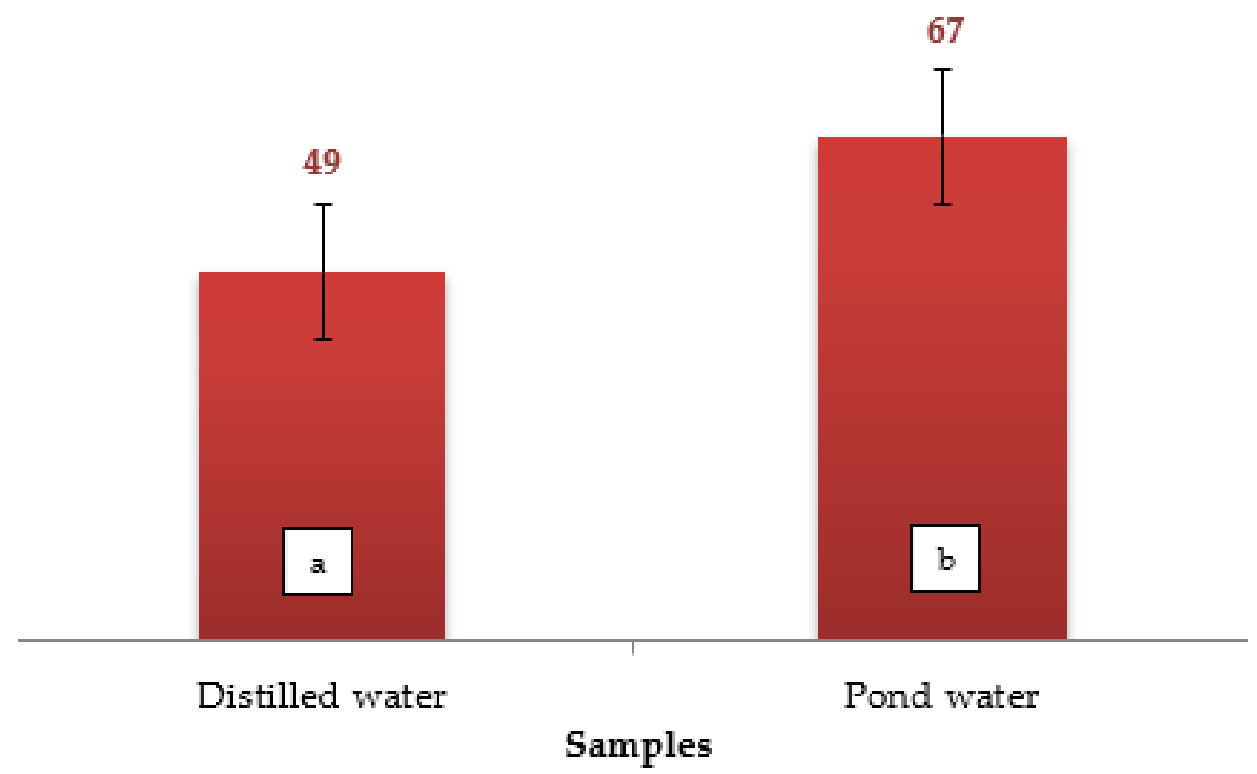

Figure 3. Germination index (GI) of Lepidium sativum L. in establishing the degree of phytotoxicity.

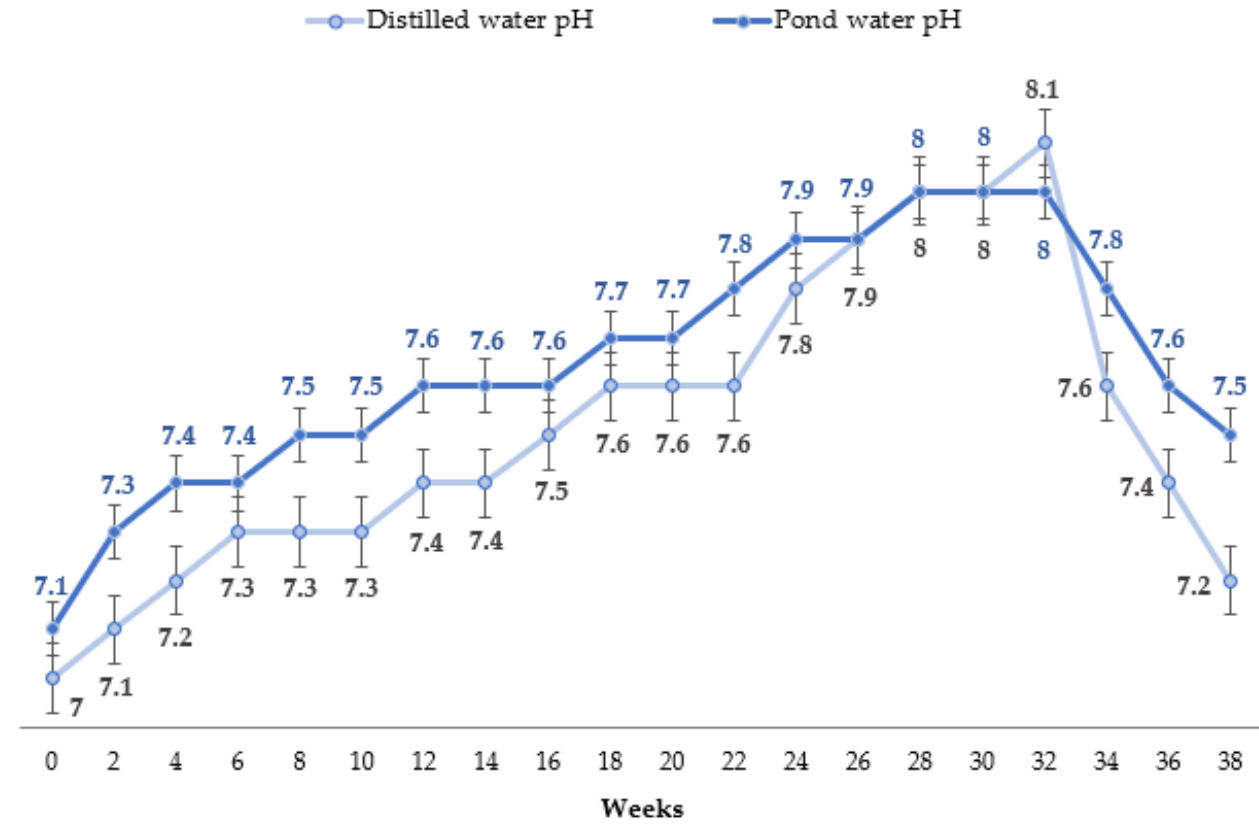

Figure 4. Values of $\mathrm{pH}$ in the leachates from tires measured in distilled water and recipient water. 

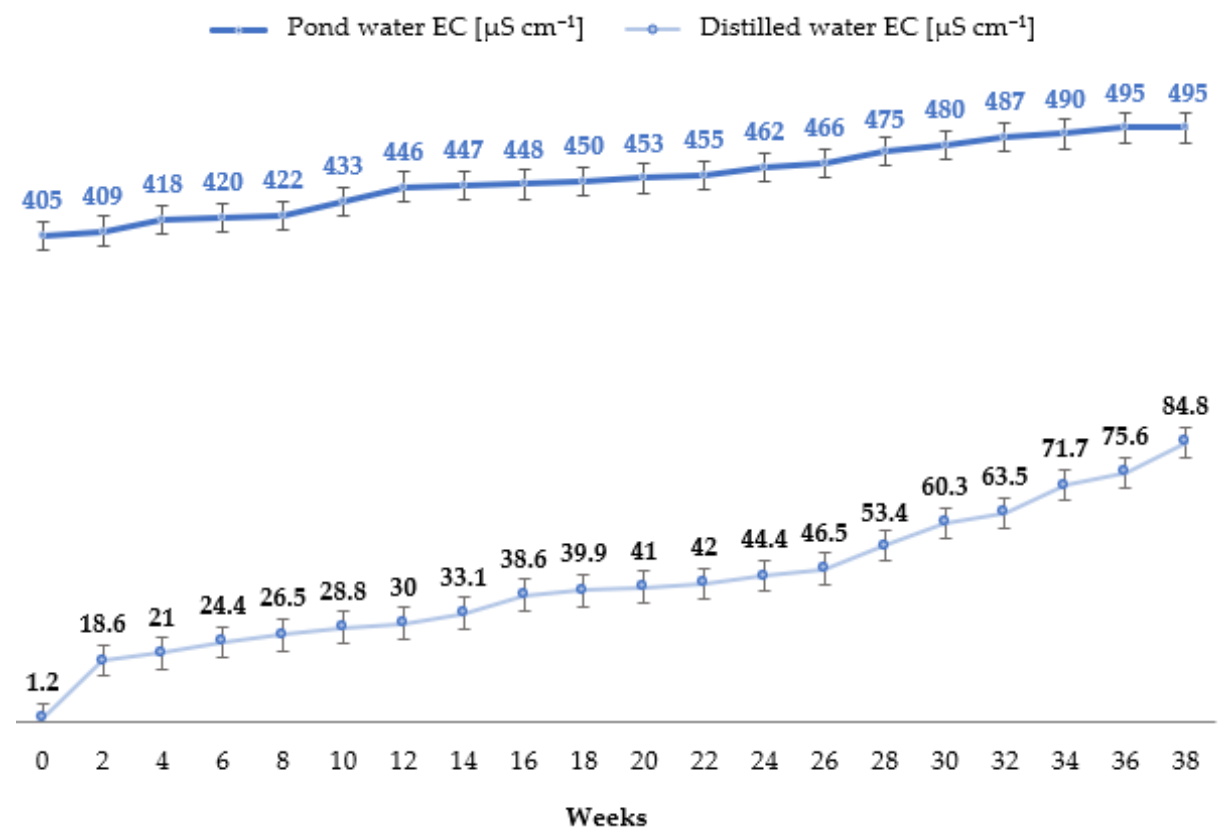

Figure 5. Recorded parameters of EC $\left(\mu \mathrm{S} \mathrm{cm}{ }^{-1}\right)$ in leachates from tire fractions in distilled water and in recipient water.

\section{Distilled water LDO $\left[\mathrm{mg} \mathrm{L}^{-1}\right] \quad$-* Pond water LDO $\left[\mathrm{mg} \mathrm{L}^{-1}\right]$}

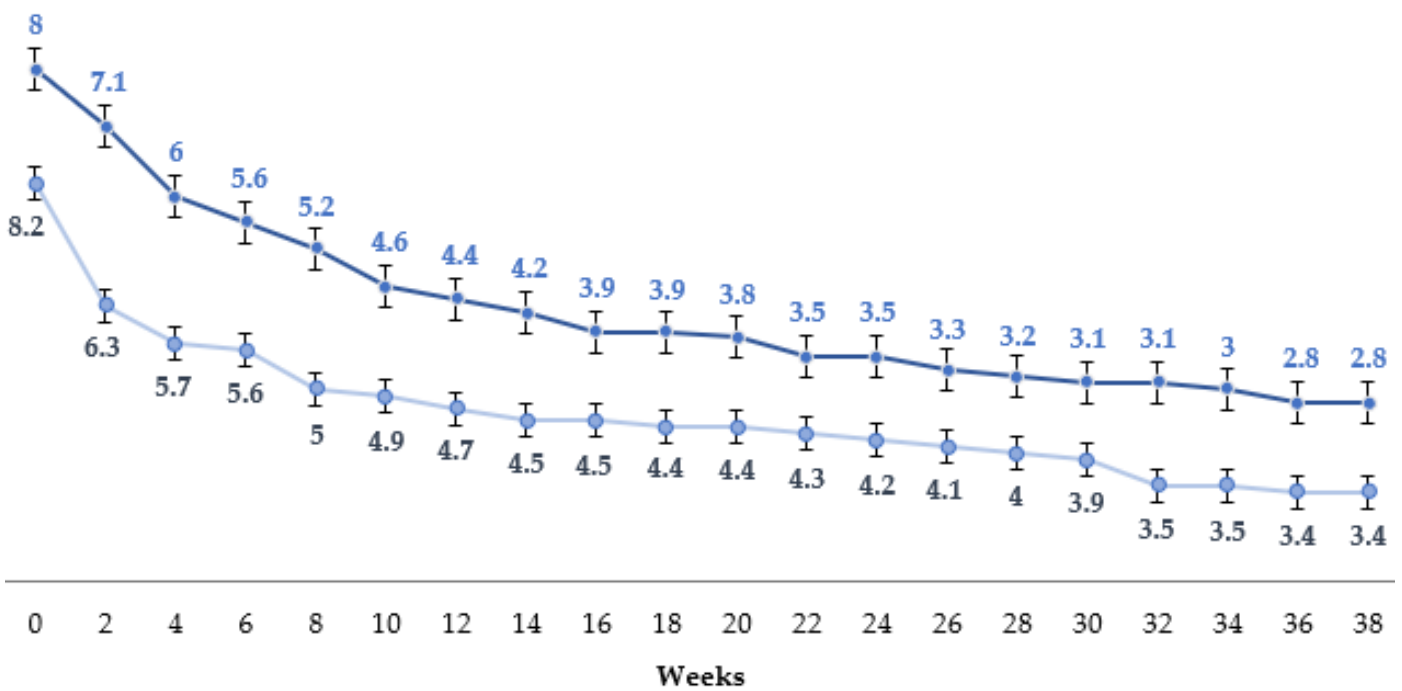

Figure 6. LDO values $\left(\mathrm{mg} \mathrm{L}^{-1}\right)$ measured in the leachates of tire fractions in distilled water and in recipient water.

\subsection{Testing the Toxicity of Aqueous Leachates from Tire Fractions by Microbiotests}

IR was determined using the Phytotoxkit ${ }^{\mathrm{TM}}$ methodology. In line with the methodology, the degree of aqueous leachate toxicity was tested on the seeds of white mustard (Sinapis alba L.) and watercress (Lepidium sativum L.). These plant species are most frequently used for testing phytotoxicity thanks to the fast germination of their seeds and fast root growth [28]. Their primary characteristic is the sensibility to pollutants occurring in the tested samples of soils and waters. These pollutants act as a stress factor affecting plant germination and development $[21,29,30]$.

Samples of leachates from tire fractions (designation: distilled water (DW), pond water (PW)) were subjected to phytotoxicity tests after 8 months from the establishment of 
the experiment at a $100 \%$ concentration. The Phytotoxkit consists of two testing sections; a mixture of OECD soil (artificial soil with $85 \%$ of silica sand, $10 \%$ of kaolin clay and $5 \%$ of calcium carbonate and peat) and aqueous leachate from tire segments was applied on the lower segment. Distilled water was used as a control sample. Seeds of Lepidium sativum L. (10 pieces) were placed on the filter paper in the middle of the testing kit. The kit was then closed, placed vertically into the holder and incubated for $72 \mathrm{~h}$ at a temperature of $25 \pm 2{ }^{\circ} \mathrm{C}$ in the Ecocell incubator with no access to light. After the end of the incubation period, partial lengths of Lepidium sativum L. roots were analyzed and measured using the Image Tool 3.0 software for Windows (UTHSCSA, San Antonio, TX, USA). The same procedure was used to test phytotoxicity on the seeds of Sinapis alba L. After the end of the experiment implemented with using the testing Phytotoxkit ${ }^{\mathrm{TM}}$, IR (\%) was calculated from the recorded values. The results of IR (\%) inform about the percentage of IR stimulation $(\%)<0$, or inhibition of root growth IR $(\%)>0$ in the plant species used. IR was determined according to the following equation $[21,28,31,32](1)$ :

$$
\operatorname{IR}[\%]=\left[\left(\mathrm{L}_{\mathrm{C}}-\mathrm{L}_{\mathrm{S}}\right) / \mathrm{L}_{\mathrm{C}}\right] \times 100
$$

where $\mathrm{L}_{\mathrm{C}}$ is the mean length of root in the control sample $(\mathrm{mm})$ and $\mathrm{L}_{\mathrm{S}}$ is the mean length of root in the tested sample $(\mathrm{mm})[21,22,28,31,32]$.

\subsection{Testing the Phytotoxicity of Aqueous Leachates from the Fractions of Tires by Watercress Test}

The testing also included a watercress test of phytotoxicity according to the methodology introduced by ALS Czech Republic, s.r.o. It is a biological method of assessing the phytotoxicity of leachate to GI (\%) using watercress (Lepidium sativum L.) [33]. A filter paper placed in the Petri dish was applied $10 \mathrm{~mL}$ of $100 \%$ of aqueous leachate from the tire fractions, and then 30 seeds of watercress (Lepidium sativum L.) were evenly distributed thereon. At the same time, a control sample of distilled water was prepared, and the Petri dishes were incubated for $48 \mathrm{~h}$ at $27 \pm 2{ }^{\circ} \mathrm{C}$ in the Ecocell incubator with no access to light. After the incubation period, the number of non-germinated seeds was analyzed, and partial lengths of individual roots of Lepidium sativum L. were recorded manually [34,35]; GI (\%) was then calculated from the recorded values. GI results (\%) give the degree of leachate phytotoxicity: very phytotoxic GI $(\%)<25$, phytotoxic $26<$ GI $(\%)<65$ and non-phytotoxic/sTable $66<\mathrm{GI}(\%)<100$. The determination of GI is given by a series of calculations according to the following equations [33] (2,3 and 4):

Germination G $(\%)$

$$
\mathrm{G}[\%]=\left(\mathrm{Ns} / \mathrm{N}_{\mathrm{C}}\right) \times 100
$$

where $N_{S}$ is the number of germinated seeds in the tested leachate $(\mathrm{mm})$ and $\mathrm{N}_{\mathrm{C}}$ is the number of germinated seeds in the control sample $(\mathrm{mm})$.

Elongation L (\%)

$$
\mathrm{L}[\%]=\left(\mathrm{Ls} / \mathrm{L}_{\mathrm{C}}\right) \times 100
$$

where $L_{S}$ is the average length of root in the tested leachate $(\mathrm{mm})$ and $L_{C}$ is the average length of root in the control sample $(\mathrm{mm})$.

Germination index GI (\%)

$$
\mathrm{G}[\%]=(\mathrm{G} \times \mathrm{L}) / 100
$$

\subsection{Physical and Chemical Analysis of Aqueous Leachates from Tire Fractions}

The samples of aqueous leachates from the fractions of tires were measured twice a month from May 2020 to February 2021 (38 weeks). The initial measurement of distilled water $\left(\mathrm{DW}_{0}\right)$ and water from the recipient $\left(\mathrm{PW}_{0}\right)$ was taken prior to the addition of tire fractions. During the set up time, the aqueous leachates were measured three times using probes, and the resulting parameter was determined by arithmetic mean. In the experiment, changes in physical and chemical parameters of conductivity (EC) were monitored, the amount of dissolved oxygen (LDO) and $\mathrm{pH}$ by the HACH TEST KIT. The EC probe was 
used to determine the degree of electric conductivity $\left(\mu \mathrm{cm}^{-1}\right)$, the LDO probe was used to determine water saturation with oxygen $\left(\mathrm{mg} \mathrm{L}^{-1}\right)$ and $\mathrm{pH}$ was used to establish acidity/alkalinity of the tested sample.

\section{Results}

\subsection{Tests of the Phytotoxicity of Leachates from Tire Fractions}

Results of IR (\%) are presented in Figure 2.

The plot shows the mean, the whiskers representing the standard error, values with different letters $(a ; b)$ indicate significant difference $(p 0.05)$ between variants, differences between variants were analysed with the parametric LSD Fisher test.

The highest IR value (\%) was calculated in the DW sample with Lepidium sativum L. $(47.7 \%)$. The lowest IR value (\%) was calculated in the PW sample with Sinapis alba L. $(11.7 \%)$. The testing of the phytotoxicity of leachates from tire fractions to the seeds of Lepidium sativum L. and Sinapis alba L. demonstrated the inhibition of root growth $(\operatorname{IR}(\%)>0)$. Lepidium sativum L. responded to the leachate more sensitively, its seeds exhibiting a higher IR value (\%).

\subsection{The Watercress Test of the Phytotoxicity of Leachates from Tire Fractions}

Results of GI (\%) are presented in Figure 3.

The plot shows the mean, the whiskers representing the standard error, values with different letters $(a ; b)$ indicate significant difference $(p 0.05)$, between variants, differences were analysed with the parametric LSD Fisher test.

The highest GI value (\%) was ascertained in the PW sample with Lepidium satioum $\mathrm{L}$. $(66.7 \%)$. The watercress test of the phytotoxicity of leachate from tire fractions in distilled water showed the leachate phytotoxicity.

\subsection{Physical and Chemical Analyses of Aqueous Leachates from Tire Fractions}

During the experiment, the $\mathrm{pH}$ and $\mathrm{EC}$ values were increasing (see Figures 4 and 5) while the LDO values were decreasing (see Figure 6).

The plot shows the mean, the whiskers representing the standard error. The highest $\mathrm{pH}$ value of leachate from tire fractions (8.1) was recorded in DW in week 32 while the lowest $\mathrm{pH}$ values (7.1 and 7.2) were measured in week 2 and week 38, respectively. During the whole time of the experiment, both DW and $\mathrm{PW}$ exhibited alkaline $\mathrm{pH}$ values. The mean $\mathrm{pH}$ was 7.5 for DW and 7.6 for PW.

The plot shows the mean, the whiskers representing the standard error. The PW sample of leachate from tire fractions exhibited the highest EC values for the whole monitored period at the end of the experiment $\left(495 \mu \mathrm{S} \mathrm{cm}^{-1}\right)$ in weeks 36 and 38. Depending on time and persistence of tire fractions in $\mathrm{PW}$, the EC values were increasing. At the beginning of the experiment (in the first month), they were on average $410.7 \mu \mathrm{S} \mathrm{cm}^{-1}$ and at the end of the experiment (in the last month), the leachates exhibited average the EC values of $492.3 \mu \mathrm{S}$ $\mathrm{cm}^{-1}$. The data indicate that EC increased from the beginning to the end of the experiment by $81.6 \mu \mathrm{S} \mathrm{cm}{ }^{-1}$. The experimental leachates already changed their colour in week 4 when they were light green to yellow. At the end of the experiment (after 38 weeks), the leachates were dark green to dark brown (see Figure 7) and featured a typical metal smell. The lowest EC value was recorded in the DW leachate from tire fractions in week $2\left(18.6 \mu \mathrm{S} \mathrm{cm}^{-1}\right)$. In the course of the experiment, the DW and PW samples exhibited increasing EC values, especially due to the gradual release of substances from the tire fractions. 


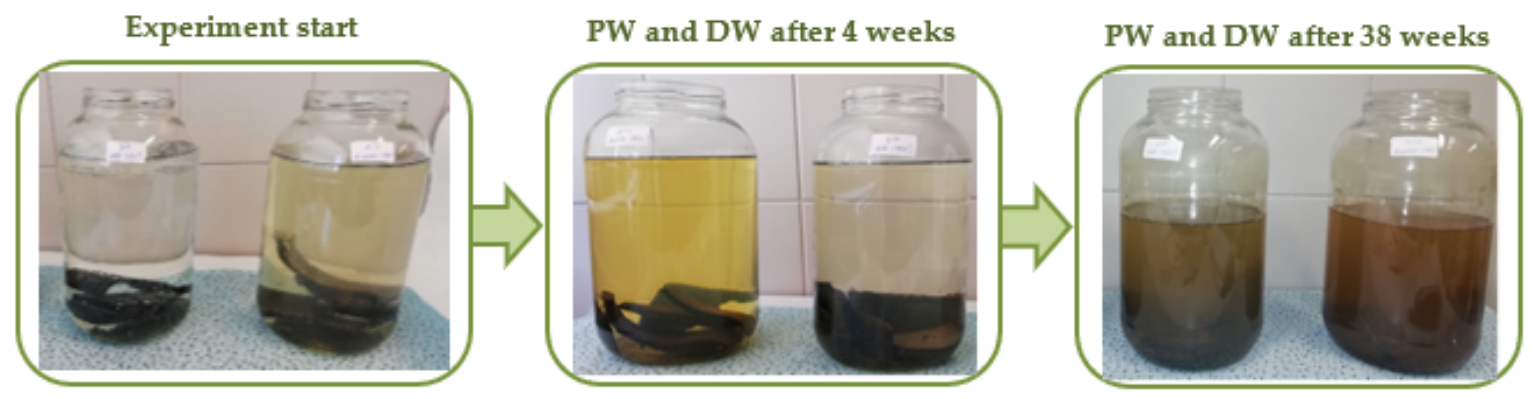

Figure 7. The course of colour changes in the experimental leachates.

Results of LDO parameters (mg L ${ }^{-1}$ ) establishing the amount of dissolved oxygen during the experiment are presented in Figure 6. The plot shows the mean, the whiskers representing the standard error. The highest $\mathrm{LDO}$ value $\left(7.1 \mathrm{mg} \mathrm{L}^{-1}\right)$ was measured in the PW leachate from tire fractions in week 2 of the experiment and the lowest LDO value $\left(2.8 \mathrm{mg} \mathrm{L}^{-1}\right)$ was recorded in the PW sample in week 38 of the experiment. In DW samples, the highest LDO value $\left(6.3 \mathrm{mg} \mathrm{L}^{-1}\right)$ in the leachate from tire fractions was recorded also in week 2 , and the lowest LDO value $\left(3.4 \mathrm{mg} \mathrm{L}^{-1}\right)$ was measured in week 38 , similarly as in $\mathrm{PW}$. The LDO values were decreasing with the increasing time for which the tire fractions stayed in DW and PW. At the beginning of the experiment (in the first month), mean LDO values were $6.2 \mathrm{mg} \mathrm{L}^{-1}$ in PW and $5.9 \mathrm{mg} \mathrm{L}^{-1}$ in DW. At the end of the experiment (in the last month), mean LDO values were $2.9 \mathrm{mg} \mathrm{L}^{-1}$ in PW and $3.4 \mathrm{mg} \mathrm{L}^{-1}$ in DW. Thus, the data show that the LDO values decreased from the beginning to the end of the experiment by $4.3 \mathrm{mg} \mathrm{L}^{-1}$ in PW and by $2.9 \mathrm{mg} \mathrm{L}^{-1}$ in DW. The gradual LDO deficit in the DW and PW samples during the experiment was caused by the gradual release of substances from the tire fractions.

\section{Discussion}

\subsection{Tests of the Phytotoxicity of Leachates from Tire Fractions}

Regarding its sensitivity to phytotoxins, Lepidium sativum L. is generally one of the most sensitive plants, which is demonstrated by IR values higher than in Sinapis alba L. However, it cannot be said that Sinapis alba L. would be a plant species less suitable for testing the phytotoxicity. Both of these species exhibited the inhibition of root growth IR $(\%)>0$, which indicated the phytotoxicity of leachates. The IR values differed by tens of percent. Here, however, the uncertainty of the measurement of partial root lengths in Lepidium sativum L. and Sinapis alba L. can be taken into consideration. The results suggest that aqueous leachates from tire fractions have a significant phytotoxic impact, namely due to the gradual release of toxic substances over time. The chosen 100\% concentration simulated a condition in which tires are dumped illegally into small recipients for a longer time, thus showing possible risks of infiltration into the soil and groundwater.

Similar research studies for testing phytotoxicity on higher plants have not been conducted so far. Nevertheless, similar principles are used in scientific publications that deal with the testing of acute phytotoxicity of leachates from waste tires on living organisms (algae, embryos and animals). One of them is Gualtieri et al. (2005) [18] where the authors performed a standard test of acute and chronic toxicity on Daphnia magna. In the test, they used $1 \%, 10 \%, 50 \%$ and $100 \%$ concentrations of leachates, comparing the immobility and mortality of algae after 24 and $48 \mathrm{~h}$. The authors concluded that a mutual correlation occurred between mortality and concentrations from $10 \%$ to $100 \%$. Already the exposure to the concentration of $10 \%$ resulted in $100 \%$ mortality. They also performed a standard test of toxicity on the growth of Raphidocelis subcapitata lasting $72 \mathrm{~h}$, in which a dilution series of $1 \%, 10 \%, 50 \%$ and $100 \%$ concentrations was used. Once again, a strong correlation was demonstrated between the leachate concentrations and algae growth inhibition. Already the concentration of $1 \%$ resulted in growth inhibition values ranging between $45 \%$ and $53 \%$. The $100 \%$ concentration resulted in the inhibition value of ca. $99 \%$ [18]. 
Wik and Dave (2005) [5] also tested the phytotoxicity of leachates from tires. They used grated rubber from a total of 12 kinds of tires, which they placed into Petri dishes together with Daphnia magna. Then the rubber was diluted with water to concentrations of $0.25 ; 0.5 ; 1 ; 2 ; 4 ; 8$ and $16 \mathrm{~g} \mathrm{~L}^{-1}$. Following exposures for 24 and $48 \mathrm{~h}$, the authors concluded that all kinds of tested rubber from tires were toxic to the alga. According to the authors, the $48 \mathrm{~h}$ exposure was significantly more toxic (nearly ten-times) than the $24 \mathrm{~h}$ exposure. The results led the authors to conclude that tires contain compounds which are bioconcentrating [5]. A year later, Wik and Dave (2006) [7] conducted a similar research of the toxicity of worn tires to Daphnia magna. The results of their research study indicated that even low concentrations of leachates are phytotoxic. Based on the results of their research studies (2005 and 2006), the authors arrived at conclusion that tire tread wear might have much more harmful impacts than expected [7]. It is therefore important to combine this research with the testing of the phytotoxic effects of leachates from waste tires on higher plants.

The tests of phytotoxicity of leachates from waste tires showed that the defense system and metabolism of animals, algae and plants are disturbed with no regard to the concentration of leachates from the waste tires. Moreover, low concentrations of leachates from the waste tires in the phytotoxicity tests only extend the decay time while high concentrations cause practically immediate mortality.

\subsection{The Watercress Test of the Phytotoxicity of Leachates from Tire Fractions}

The degree of phytotoxicity directly mirrors the content of toxic intermediate products in the leachate with the absence of phytotoxins indicating the germination index (GI \%) of about $100 \%$ [34]. Plíva et al. (2006) inform that the germination index (expressed in the percentage of control which is distilled water) indicates a very high degree of phytotoxicity $(60-80 \%)$ at values of up to $50 \%$, which represents a certain risk of damage to sensitive plants, and non-phytotoxic/stable leachate at values over $80 \%$ and higher [36]. Bouda and Formánková (2014) report that the germination index below 25\% indicates a leachate as highly phytotoxic: phytotoxic from $26 \%$ to $65 \%$ and non-phytotoxic/stable over $66 \%$ [33].

According to Plíva et al. (2006), the values of leachate from tire fractions are highly phytotoxic (GI 48.96\%) in the DW sample and phytotoxic (GI 66.71\%) in the PW sample [36]. In contrast, according to Bouda, Formánková (2014), the values of leachate from tire fractions in the DW sample would be classified as phytotoxic and in the PW sample as nonphytotoxic/stable. However, the uncertainty of the measurement of partial root lengths of Lepidium sativum L. could be taken into account. Similarly, as in the tests of phytotoxicity, the results suggest that aqueous leachates from tire fractions have a significant phytotoxic impact, namely due to the gradual release of toxic substances over time.

\subsection{Physical and Chemical Properties of Aqueous Leachates from Tire Fractions}

Duda et al. (2020) performed physical and chemical analyses of leachates from tires in a mud sump where they monitored $\mathrm{pH}, \mathrm{EC}$ and LDO changes after the first rinsing of tires and on the last day of the test (after 120 days). The $\mathrm{pH}$ value of leachate after the first rinse of tires was 8.98 and it increased to 9.16 after the last rinse. The value slightly exceeded the permissible limit recommended for surface water used for the supply of drinking water. The EC value also exhibited an increase-from $454 \mu \mathrm{cm}^{-1}$ to $503 \mu \mathrm{S}$ $\mathrm{cm}^{-1}$, which suggests that solids and dissolved solids passed from the surface of tires into water. On the other hand, the LDO values exhibited a decrease in the course of time from $6.73 \mathrm{mg} \mathrm{L}^{-1}$ to $1.98 \mathrm{mg} \mathrm{L}^{-1}$, which was due to the increasing amount of substances leached from the tires [37]. Koníčková (2010) adds that the alkaline pH values of aqueous leachates from the test tire specimens are caused particularly by potassium hydroxide released into the aquatic environment [38]. Sheehan et al. (2005) report that so-called iron precipitates develop upon the contact of tires with groundwater. The increased concentration of iron is responsible for the decreased amount of dissolved oxygen and increased $\mathrm{pH}$ [39]. The decreased LDO value during the experiment was also confirmed by Hossain et al. (2011), 
who analysed the leachate from tire chips in a storage tank. They also recorded that the leachate colour was changing during the experiment with the decreasing rate of LDO, which was blueish-green and light yellow in the first 21 days [40].

\section{Conclusions}

The goal of this study was to establish the acute phytotoxicity of leachates from waste tire fractions. The effects of phytotoxicity were measured in distilled water (simulation of laboratory conditions) and water collected from a recipient (simulation of real conditions). Results of root growth inhibition on the seeds of Lepidium sativum L. and Sinapis alba L. indicated the inhibited development of roots in the tested plant species, which demonstrated the phytotoxicity of both leachates from the tire fractions.

The watercress test with the seeds of Lepidium sativum L. showed that both tested leachates from tire fractions were phytotoxic to highly phytotoxic. These leachates have a significant phytotoxic impact on the environment due to the gradual release of toxic substances over time.

During the experiment, the physical and chemical analyses of aqueous leachates from tire fractions demonstrated a correlation between the increasing amount of dissolved solids from the tires and the decreasing amount of dissolved oxygen, which also has to do with the increasing values of electric conductivity and $\mathrm{pH}$ that were growing with the increasing amount of dissolved solids (potassium hydroxide, iron).

Based on the research results that demonstrated a high rate of phytotoxicity of the tested aqueous leachate from waste tires, this type of waste is not recommended for the establishment of lagoons, reinforcement of river beds and banks, or for its recycling and further usage for example as granulate that is in the direct contact with the environment. A more appropriate option for waste tires after the end of their service life is to use them as a valuable source of fuel in cement factories or in pyrolysis. Such methods of handling eliminate the risk of negative impacts on the aquatic environment. However, then a question of financial resources of individual countries arises and their possibilities of processing the waste tires. It is also important to expand publicly available tire takeback points, raise awareness of the risks associated with illegal dumping and call for their prevention. Strict sanctions are also needed for countries that commit to setting up such landfills under national waste management laws. In connection with the negative consequences following out from the existence of waste tires, it is necessary to go back to the very beginning of the manufacturing process. The primary concern of tire manufacturers should be innovative solutions focused both on the reduction in rubber toxicity and on new technologies in manufacturing tires without toxic substances.

Author Contributions: Conceptualization, M.Š.; D.A. and M.D.V.; methodology, M.Š.; D.A.; J.W.; validation, D.A., and M.D.V.; formal analysis, M.Š., D.A.; J.W.; investigation, M.Š.; data curation, D.A.; M.D.V.; J.W.; writing-original draft preparation, M.Š.; D.A. and M.D.V.; writing-review and editing, M.D.V.; visualization, M.Š. and M.D.V.; supervision, D.A. All authors have read and agreed to the published version of the manuscript.

Funding: This research received no external funding.

Conflicts of Interest: The authors declare no conflict of interest.

\section{References}

1. Lallanilla, M. All About Tire Recycling. The Spruce. 2019. Available online: https://www.thespruce.com/tire-recycling-letsburn-some-rubber-1708979 (accessed on 15 March 2021).

2. Kukreja, R. Tire Recycling. Conserve Energy Future. 2015. Available online: https://www.conserve-energy-future.com/ tirerecycling.php (accessed on 15 March 2021).

3. Zhang, J.; Han, I.K.; Zhang, L.; Crain, W. Hazardous chemicals in synthetic turf materials and their bioaccessibility in digestive fluids. J. Expo Sci. Environ. Epidemiol. 2008, 18, 600-607. [CrossRef] [PubMed]

4. Kanematsu, M.; Hayashi, A.; Denison, M.S.; Young, T.M. Characterization and potential environmental risks of leachate from shredded rubber mulches. Chemosphere 2009, 76, 952-958. [CrossRef] [PubMed] 
5. Wik, A.; Dave, G. Environmental labeling of car tires-Toxicity to Daphnia magna can be used as a screening method. Chemosphere 2005, 58, 645-651. [CrossRef] [PubMed]

6. Llompart, M.; Sanchez-Prado, L.; Lamas, J.P.; Garcia-Jares, C.; Roca, E.; Dagnac, T. Hazardous organic chemicals in rubber recycled tire playgrounds and pavers. Chemosphere 2013, 90, 423-431. [CrossRef]

7. Wik, A.; Dave, G. Acute toxicity of leachates of tire wear material to Daphnia magna-Variability and toxic components. Chemosphere 2006, 64, 1777-1784. [CrossRef] [PubMed]

8. Sathiskumar, C.; Karthikeyan, S. Recycling of waste tires and its energy storage application of by-products-A reviev. Sustain. Mater. Technol. 2019, 22, e00125.

9. Nguyen, C. Watch How Old Tires are Retreaded so They can be Used again. Bus. Insider. 2019. Available online: https: / / www.businessinsider.com/tires-retreaded-recycling-marangoni-2019-3 (accessed on 23 March 2021).

10. Kuraš, M. Waste and Their Processing, 1st ed.; Vodní Zdroje Ekomonitor: Chrudim, Czech Republic, 2014; pp. $102-103$.

11. Ichinose, D.; Yamamoto, M. On the relationship between the provision of waste management service and illegal dumping. Resour. Energy Econ. 2011, 33, 79-93. [CrossRef]

12. Vaverková, M.D.; Maxiánová, A.; Winkler, J.; Adamcová, D.; Podlasek, A. Environmental consequences and the role of illegal waste dumps and their impact on land degradation. Land Use Policy 2019, 89, 104234. [CrossRef]

13. Yang, W.; Fan, B.; Desouza, K.C. Spatial-temporal effect of household solid waste on illegal dumping. J. Clean. Prod. 2019, 227, 313-324. [CrossRef]

14. Keesstra, S.D.; Bouma, J.; Wallinga, J.; Tittonell, P.; Smith, P.; Cerdà, A.; Montanarella, L.; Quinton, J.N.; Pachepsky, Y.; van der Putten, W.H.; et al. The significance of soils and soil science towards realization of the United Nations Sustainable Development Goals. Soil 2016, 2, 111-128. [CrossRef]

15. Sieber, R.; Kawecki, D.; Nowack, B. Dynamic probabilistic material flow analysis of rubber release from tires into the environment. Environ. Pollut. 2020, 258, 113573. [CrossRef]

16. Nelson, S.M.; Mueller, G.; Hemphill, D.C. Identification of tire leachate toxicants and a risk assessment of water quality effects using tire reefs in canals. U.S. Bureau of Reclamation. Bull. Environ. Contam. Toxicol. 1994, 52, 574-581. [CrossRef]

17. Nadal, M.; Rovira, J.; Díaz-Ferrero, J.; Schuhmacher, M.; Domingo, J.L. Human exposure to environmental pollutants after a tire landfill fire in Spain: Health risks. Environ. Int. 2016, 97, 37-44. [CrossRef] [PubMed]

18. Gualtieri, M.; Andrioletti, M.; Vismara, C.; Milani, M.; Camatini, M. Toxicity of tire debris leachates. Environ. Int. 2005, 31, 723-730. [CrossRef] [PubMed]

19. Capolupo, M.; Sørensen, L.; Jayasena, K.D.R.; Booth, A.M.; Fabbri, E. Chemical composition and ecotoxicity of plastic and car tire rubber leachates to aquatic organisms. Water Res. 2020, 169, 115270. [CrossRef] [PubMed]

20. Moghaddasi, S.; Khoshgoftarmanesh, A.H.; Karimzadeh, F.; Chaney, R. Fate and effect of tire rubber ash nano-particles (RANPs) in cucumber. Ecotoxicol. Environ. Saf. 2015, 115, 137-143. [CrossRef]

21. Šourková, M.; Adamcová, D.; Zloch, J.; Skutnik, Z.; Vaverková, M.D. Evaluation of the phytotoxicity of leachate from a municipal solid waste landfill: The case study of Bukov Landfill. Environments 2020, 7, 111. [CrossRef]

22. Vaverková, M.D.; Adamcová, D.; Radziemska, M.; Voběrková, S.; Mazur, Z.; Zloch, J. Assessment and evaluation of heavy metals removal from Landfill Leachate by Pleurotus ostreatus. Waste Biomass Valor. 2018, 9, 503-511. [CrossRef]

23. Radziemska, M.; Vaverková, M.D.; Adamcová, D.; Brtnický, M.; Mazur, Z. Valorization of fish waste compost as a fertilizer for agricultural use. Waste Biomass Valor. 2019, 10, 2537-2545. [CrossRef]

24. Adamcová, D.; Vaverková, M.D.; Břoušková, E. The toxicity of two types of sewage sludge from wastewater treatment plant for plants in Czech Republic. J. Ecol. Eng. 2016, 17, 33-37. [CrossRef]

25. Rashad, F.M.; Saleh, W.D.; Moselhy, M.A. Bioconversion of rice straw and certain agro-industrial wastes to amendments for organic farming systems: 1. Composting, quality, stability and maturity indices. Bioresour. Technol. 2010, 101, 5952-5960. [CrossRef]

26. Hiley, P.D. The use of barley root elongation in the toxicity testing of sediments, sludges, and sewages. In Ecotoxicology of Soil Organism; Donker, M.H., Eijsackers, H., Helmbach, F., Eds.; Lewis Publishers: New York, NY, USA, 1994; pp. 191-197.

27. Shahrokhi-Shahraki, R.; Kwon, P.S.; Park, J.; O'Kelly, B.C.; Rezania, S. BTEX and heavy metals removal using pulverized waste tires in engineered fill materials. Chemosphere 2020, 242, 125281. [CrossRef] [PubMed]

28. MicroBioTests Inc. Phytotoxkit. Seed Germination and Early Growth Microbiotest with Higher Plants; Standard Operation Procedure: Nazareth, Belgium, 2004. Available online: https://www.microbiotests.com/wp-content/uploads/2019/05/Phytotoxicity-test_ Phytotoxkit-solid-samples_Standard-Operating-Procedure.pdf (accessed on 17 March 2021).

29. Jurníčková, E. Influence of Selected Abiotic Stressors on the Germination of Seeds of Oilseed Rape (Brassica napus L.). Bachelor's Thesis, Palacký University in Olomouc, Olomouc, Czech Republic, 2015. (In Czech). Available online: https://theses.cz/id/ 5ncejc/BP_Jurnkov.pdf (accessed on 17 March 2021).

30. Bakalová, L. Phytotoxicity Tests and Their Use to Evaluate the Effect of Xenobiotics. Master's Thesis, Masaryk University in Brno, Brno, Czech Republic, 2008. (In Czech). Available online: https:/ /is.muni.cz/th/106666/prif_m/Text_prace_DIPLOMKA.pdf (accessed on 17 March 2021).

31. Zloch, J.; Adamcová, D.; Šindelář, O.; Šourková, M.; Vaverková, M.D. Testing of phytotoxicity of mining waste to determine the direction of future development. AIMS Environ. Sci. 2020, 7, 324-334. [CrossRef] 
32. Vaverková, M.D.; Zloch, J.; Adamcová, D.; Radziemska, M.; Vyhnánek, T.; Trojan, V.; Winkler, J.; Đordević, B.; Elbl, J.; Brtnický, M. Landfill leachate effects on germination and seedling growth of hemp cultivars (Cannabis Sativa L.). Waste Biomass Valor. 2019, 10, 369-376. [CrossRef]

33. Bouda, T.; Formánková, M.; ALS Czech Republic, s.r.o. Determination of Competitive Phytotoxicity-Growth Inhibition Keying and Independence Index of Lepidium sativum. Presentation 2014. (In Czech). Available online: http://www.ekomonitor.cz/sites/ default/files / filepath/prezentace/13_bouda.pdf (accessed on 19 March 2021).

34. Inteko Innovative Composting. Inovation of Technology for Standardization of Compost Quality. Project ATCZ42 INTEKO. 2019. Available online: https:/ / www.at-cz.eu/data/projects/f/17/385.pdf (accessed on 18 March 2021).

35. Kopačka, M. Possibilities, Methods and Technological Procedures in Biomass Composting. Bachelor's Thesis, South Bohemian University, České Budějovice, Czech Republic, 2009. (In Czech). Available online: https://theses.cz/id/5j3qid/ downloadPraceContent_adipIdno_8890 (accessed on 18 March 2021).

36. Plíva, P.; Banout, J.; Habart, J.; Jelínek, A.; Kollárová, M.; Roy, A.; Tomanová, D. Establishment, Course and Management of the Composting Process, 1st ed.; Research Instituce of Agricultural Technology: Prague, Czech Republic, 2006; (In Czech). Available online: https: / / docplayer.cz/2333105-Vyzkumny-ustav-zemedelske-techniky-praha-zakladani-prubeh-a-rizeni-kompostovacihoprocesu.html (accessed on 20 March 2021).

37. Duda, A.; Kida, M.; Ziembowicz, S.; Koszelnik, P. Application of material from used car tyres in geotechnics-an environmental impact analysis. PeerJ 2020, 8, e9546. [CrossRef] [PubMed]

38. Koníčková, H. Use of Waste Rubber Crumb from Tires as a Filler in Geopolymer. Master's Thesis, Tomas Bata University in Zlín, Zlín, Czech Republic, 2010. (In Czech). Available online: http:/ / digilib.k.utb.cz/bitstream/handle/10563/14289/kon\%ED\%20 kov\%E1_2010_dp.pdf?sequence=1 (accessed on 19 March 2021).

39. Sheehan, P.J.; Warmerdam, J.M.; Ogle, S.; Humphrey, D.N.; Patenaude, S.M. Evaluating the risk to aquatic ecosystems posed by leachate from tire shred fill in roads using toxicity tests, toxicity identification evaluations, and groundwater modeling. Environ. Toxicol. Chem. 2009, 25, 400-411. [CrossRef] [PubMed]

40. Hossain, A.; Warith, M.; Liu, J.; Mondal, B. Determination of the suitable size of tire chips for landfill leachate treatment. In Proceedings of the Geotechnical Conference 2011 Pan-Am CGS, Department of Civil Engineering, Ryerson University, Toronto, ON, Canada, 2-6 October 2011. Available online: http://geoserver.ing.puc.cl/info/conferences/PanAm2011/panam2011/pdfs/ GEO11Paper1073.pdf (accessed on 19 March 2021). 